\title{
Does Group Size Affect Students' Inquiry and Collaboration in Using Computer-Based Asymmetric Collaborative Simulations?
}

\author{
Meeli Rannastu ${ }^{(凶)}$, Leo Aleksander Siiman, Mario Mäeots, \\ Margus Pedaste, and Äli Leijen \\ University of Tartu, Tartu, Estonia \\ meeli.rannastu@ut.ee
}

\begin{abstract}
This study investigated students' collaborative inquiry learning with $5^{\text {th }}$ grade $\left(\mathrm{N}=58, \mathrm{M}_{\text {age }}=11.3\right.$ years $)$ and $6^{\text {th }} \operatorname{grade}\left(\mathrm{N}=74, \mathrm{M}_{\text {age }}=12.4\right.$ years $)$ participants. Students were divided into two- and four-person groups to study whether group size affects their learning with asymmetric collaborative simulations. They worked in online digital learning spaces using tablet computers and communicated face-to-face. The Collaborative Rate of Photosynthesis Lab from the Go-Lab portal (golabz.eu) was used to establish the condition of asymmetric collaboration, and tasks related to it were developed to assess students' inquiry. To assess students' collaboration, we used an adapted self-assessed collaboration skills instrument to measure three dimensions: contribution, interaction with others and team learning. The results show that collaboration did not statistically significantly differ depending on group size in the $5^{\text {th }}$ grade, but did in the $6^{\text {th }}$ grade, with 2-person groups reporting better collaboration. Regarding students' inquiry, analysis of performance on the asymmetric collaborative tasks showed that there were no statistically significant differences between groups in either grade. However, the inquiry task scores were generally low (28\% and $40 \%$ for $5^{\text {th }}$ and $6^{\text {th }}$ graders respectively), indicating that asymmetric collaborative inquiry is challenging for students in these grades.
\end{abstract}

Keywords: Collaboration skills · Asymmetric collaboration · Inquiry learning · Online labs $\cdot$ Smart devices

\section{Introduction}

Preparing young people for the future demands integrating 21st-century skills like collaboration and communication, problem-solving and critical thinking into the school curriculum. However, a challenge remains in determining effective ways of teaching these skills, as well as reliably assessing them [1]. Collaboration skills have received recent attention from international educational assessment initiatives like PISA and ATC21S, which have both attempted to measure students' collaborative problemsolving skills [2, 3]. In general, supporting and developing students' collaboration skills is among several important goals relevant to all educators. In science,

The original version of this chapter was revised: The original version of this chapter was previously published non-open access. It has now been changed to open access under a CC BY 4.0 license and the copyright holder has been updated to 'The Author(s).' The book has also been updated with this change. The correction to this chapter is available at https://doi.org/10.1007/978-3-030-35758-0_38 
collaboration is valued because research on the way scientists work in groups suggests that making successful discoveries is more likely when scientists distribute reasoning among several people, so as to better generate and evaluate alternative representations of a problem [4].

To identify situations as collaborative, Dillenbourg [5] identifies four features: peers at more or less the same level, able to perform the same actions, having a common goal and working together. To further characterize the first two features, he suggests that the degree of symmetry in a collaborative situation is a key factor, and although most collaborative situations are generally symmetrical, a slight degree of asymmetry may be desirable in triggering conflict, which in turn can facilitate learning through conflict resolution.

Technology-enhanced solutions to facilitate collaboration skills have demonstrated promising results. Chen et al. [6] synthesized 425 empirical studies in a meta-analysis and found that computer-supported collaboration had significant positive effects on knowledge gain (ES [effect size] $=0.42)$, skill acquisition $(\mathrm{ES}=0.64)$, and student perceptions $(\mathrm{ES}=0.38)$.

\subsection{Effect of Group Size on Collaboration}

Previous research suggests that the size of a collaborative group can affect individual learning outcomes and also group results. However, there is no consensus about what an optimal group size should be. Some studies suggest that pairs are best because then disruption of thought is minimized [7]. Slavin [8] found that learning outcomes were better for pairs compared to four or more member groups. At the same time, other studies suggest that larger groups (i.e., three or more students) give better opportunities to bring out multiple perspectives and form a better final result [9]. A meta-analysis by Sung et al. [10] analyzing different mobile computer-supported collaborative learning studies found that larger groups (i.e. four or more members) had better outcomes than smaller groups (i.e. two or three members).

\subsection{Measuring Collaborative Skills in Educational Contexts}

As the definition of collaborative learning has multiple views, the dimensions of collaboration skills connect to cultural, domain-specific and numerous other factors. Several self-assessment tools have been developed to measure different dimensions of collaboration skills. One of the difficulties in assessing collaboration skills is the absence of a well-validated and reliable instrument applicable to a variety of situations. For example, the team self-diagnostic learning framework measures only teamwork skills [11]. The Collaborative Self-Assessment Tool (CSAT) was developed as a general-purpose tool to help teachers model successful collaboration skills, and focused on both intrapersonal (motivation/participation; quality of work; time management; preparedness; reflection) and interpersonal (contribution; team support; team dynamics; interactions with others; role flexibility) skills [12]. Hinyard et al. [13] adapted CSAT to focus on student perceptions of collaboration skills and created an 11-item scale consisting of three dimensions of collaboration: information sharing, team learning, and team support. 


\subsection{Asymmetric Collaboration}

One way of assessing students' collaborative problem-solving skills, developed by the Assessment and Teaching of 21st Century Skills (ATC21S) project, involved using computer-based tasks to distribute resources and information differently (i.e. asymmetrically) between two collaborators [2]. For example, in a computer simulation about balancing a beam, one student could place weights on only the left side of the balance, whereas another student, working remotely on another computer, could place weights on only the right side. Both students could see the effect of the weights on their individual computer screens, but neither could complete the task without depending on the other. Positive interdependence is mentioned by Johnson and Johnson [14] as one of five essential elements of cooperative learning. The authors define positive interdependence as the perception that team members are obliged to rely on one another in order to succeed.

Tasks involving asymmetric collaborative simulations bear a resemblance to the hidden profile task. The hidden profile task describes a condition where prior to a decision-making group beginning a discussion, information is asymmetrically distributed among group members, with some information being common to all members (shared information) and some information unique to individual members (unshared information); the shared information favoring a less optimal decision than when both shared and unshared information are considered together [15]. Research using the hidden profile task has found that groups rarely discover the optimal decision because they tend to focus on shared information at the expense of unshared information [1517]. Improving performance on the hidden profile task generally requires getting group members to more thoroughly consider unshared information.

The effect of group size on the hidden profile task has been mixed [16]. Cruz et al. [18] found that small groups were better at solving the hidden profile task and suggested that social loafing in larger groups prevents a thorough discussion of unshared information. On the other hand, Stasser and Stewart [19] found that larger groups mentioned and repeated more unshared information than smaller groups, noting that the larger groups tended to have longer discussions. Mennecke [20] found that group size did not affect the proportion of shared or unshared information mentioned.

\subsection{The Current Study}

Asymmetric collaborative simulations offer a potentially promising way to extend inquiry learning with computer simulations to include a stronger emphasis on collaboration. However, it is not clear what the optimal group size should be for learning with asymmetric collaborative simulations to be most effective. The main research question addressed in this study is: To what extent does group size affect students' inquiry and collaboration in using computer-based asymmetric collaborative simulations? 


\section{Method}

Two experiments, one with a $5^{\text {th }}$ grade class and another with a $6^{\text {th }}$ grade class of students at a public school in Tartu, Estonia were conducted. A total of 132 students participated. In the $5^{\text {th }}$ grade experiment there were 58 students ( 28 girls, 30 boys, $\mathrm{M}=11.3$ years) and in the $6^{\text {th }}$ grade experiment there were 74 students (43 girls, 31 boys, $M=12.4$ years). The large size of these classes was due to the fact that this school applies an open classroom methodology for teaching science in grades 4 to 6 , which can accommodate larger classes. The open classroom approach enables flexible use of space, furniture, equipment and digital technology to promote collaboration and group-based learning. In our study, students were divided into 2-person and 4-person groups. The groups worked on an inquiry learning activity using iPad tablet computers and communicated face-to-face. Students in 2-person groups had one iPad device per student, while students in 4-person groups had one iPad device per pair of students.

\subsection{Materials}

\section{Asymmetric Collaborative Simulations}

Two asymmetric collaborative simulations, available from the Go-Lab Portal (golabz. eu), were used in this study. The first one, the Collaborative Seesaw Lab (https://www. golabz.eu/lab/seesaw-lab; see Fig. 1 top), was used as a demonstrative example to familiarize students with the type of task associated with using an asymmetric collaborative simulation. It allowed students to place masses on a seesaw and share masses between each other. In one version of this simulation, a student could place masses only on the left side of the seesaw. In the other version, a student could place masses on only the right side. The effects of the masses on the seesaw were simultaneously seen by both students, but the location and weight of the masses of the collaborating partner were hidden (see Fig. 1 top). The task associated with this simulation required students to determine if it is possible to balance the seesaw using either two or three masses. The second simulation, the Collaborative Rate of Photosynthesis Lab (https://www.golabz. eu/lab/rate-of-photosynthesis-collaborative-lab; see Fig. 1 bottom), was used in the learning phase and the tasks associated with it were scored for the purposes of assessing students inquiry in this study. The Collaborative Rate of Photosynthesis Lab shows an aquatic plant immersed in a glass of water situated in a room with a desk lamp and a window. In one version of this simulation (labeled as Version A), a student can control the season of the year, whereas in the other version (labeled as Version B), a student can control the intensity of the desk lamp. The effects of both variables are seen simultaneously to both students. Furthermore, by clicking on the play button in the simulation, the aquatic plant begins to release bubbles due to the process of photosynthesis releasing oxygen gas. A time counter indicates the number of seconds that have elapsed and animation in the simulation, as well as text labeled "Number of bubbles", indicate how many bubbles have been emitted. 


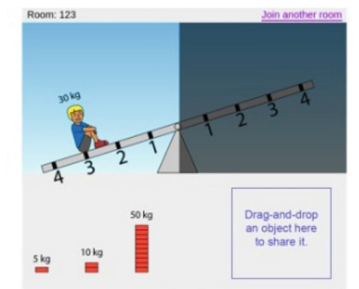

(a)

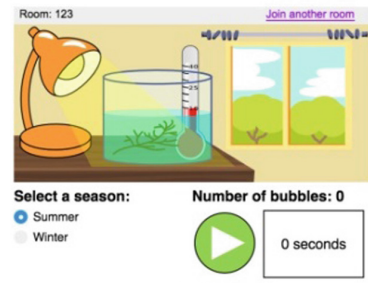

(a)

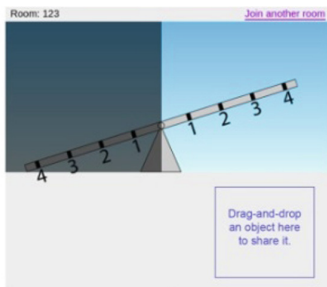

(b)

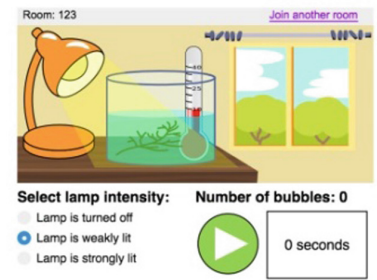

(b)

Fig. 1. (Top) The Collaborative Seesaw Lab simulation: (a) Version A allows a student to interact with only the left side of the seesaw, and (b) Version B allows a student to interact with only the right side of the seesaw. (Bottom) The Collaborative Rate of Photosynthesis Lab simulation: (a) Version A allows a student to control only the season of the year (indicated by seeing green foliage and blue sky through the window during summer and seeing snow during winter), whereas (b) Version B allows a student to control only the light intensity of the lamp.

\section{Teacher Co-creation of Learning Materials}

The lesson plan of how to instruct and use the asymmetric collaborative simulations with students was co-created with the teacher in whose classes the two experiments were conducted. The teacher gathered appropriate instructional material to introduce photosynthesis to his students and provided feedback on how to best implement the lesson in his classes. He had prior experience using iPads for group work in his classes and saw the benefits of enriching his $5^{\text {th }}$ and $6^{\text {th }}$ grade science classes with technologyenhanced learning materials.

\section{Learning Environment}

For the current study, two inquiry learning spaces (ILSs) were created in the Go-Lab authoring environment (https://graasp.eu/). The Go-Lab (Global Online Science Labs for Inquiry Learning at School) environment is an online open educational resource aimed at facilitating the use of online labs and digital resources by science teachers [21]. Inquiry learning spaces in Go-Lab can contain rich multimedia and educational resources that work well for in-class group work using smart devices [22]. The two spaces we created were identical except for the fact that they included different versions of the asymmetric collaborative simulations and had slightly different tasks, as explained below. Links to English translated versions of these ILSs (the actual ILSs used in the study were in Estonian) are available at https://graasp.eu/s/cw6fmu and https://graasp.eu/s/unlxjc and referred to as Version A and Version B respectively. 


\subsection{Measures}

Two measures were used in this study, one to assess students' inquiry and another to assess their collaboration. Students' inquiry was assessed according to their performance on an open-response question requiring use of the Collaborative Rate of Photosynthesis Lab. Students were asked to answer either the question "In this simulation, how does the rate of photosynthesis in the aquarium plant depend on the light intensity of the lamp?" (henceforth referred to as Task A) or the question "In this simulation, how does the rate of photosynthesis in the aquarium plant depend on the season of the year?" (henceforth referred to as Task B). The version of the task was paired with the version of the simulation in which the variable mentioned in the task was not available for the student to manipulate. We presumed that this interdependency condition would oblige students to collaborate more in solving their respective tasks, since the variable being asked about could only be controlled by their partner(s). Answers to the task were coded according to the following rubric: 2 points for completely correct, 1 point for partially correct and 0 points for incorrect. The correct answer for Task A is that the rate of photosynthesis increases as light intensity increases. The correct answer for Task B is that the rate of photosynthesis does not depend on the season of the year. This apparently contradictory finding is because the aquatic plant was placed indoors, and the temperature of the water did not change as the season of the year changed. In the simulation, a thermometer paced in the glass of water showed that the water temperature remained constant. In any case, the task expects students to perform experiments, and base their conclusions on data obtained from experimental trials, which for the case of the season of the year variable indicates that the number of bubbles released over a predefined time interval remains constant. Interrater reliability of Tasks A and B showed very good agreement, Cohen's kappa of .76 and .84 respectively. The disagreements were discussed to reach consensus on assigning a final code.

To measure students' collaboration, the self-assessed collaboration skills questionnaire of Hinyard et al. [13] was adapted for use. It presumably measures three dimensions of collaboration: information sharing, team support and team learning. We selected 4 items, out of 11 , related to these dimensions which were judged to be most relevant in a short-term intervention like the one in our study. Items related to collaboration over a longer period of time were excluded or rephrased in a way that students could interpret them in the context of the collaboration in this study. The adapted items we used were "I shared information easily with my partner", "I acknowledged my partners' efforts", "I supported my partner" and "I sought out different views than my own during the collaboration". The internal consistency reliability of these items was good (Cronbach's alphas equal to .80 and .83 for $5^{\text {th }}$ and $6^{\text {th }}$ grade students respectively). Since 4-member groups required a pair of students to share an iPad while working in Go-Lab, we decided not to integrate the questionnaire online, but instead printed it on paper. This enabled us to collect responses from all individuals involved in the study. 


\subsection{Procedure}

Both experiments followed the same procedure. The total time of an experiment was 135 min. Figure 2 presents a flowchart of the lesson plan showing how the experiment was conducted. The structure of inquiry phases in the lesson plan was based on the inquiry-based learning framework of Pedaste et al. [23], in which learning is structured according to an inquiry cycle model. For completeness, all the phases and associated activities are mentioned in Fig. 2, but the main focus of this study was on students' inquiry as assessed on the asymmetric collaborative tasks found in phase 6 , and students' collaboration as assessed in phase 7 .

The first phase of the lesson involved the teacher forming 2-person and 4-person groups and distributing two iPads per group. This was followed by the second phase, in which the teacher introduced students to the Go-Lab learning environment and to an example task involving an asymmetric collaborative simulation. Next, in the third phase, students worked collaboratively to complete the example task. The fourth phase involved the teacher demonstrating to students the correct answers to the example task and highlighting the importance of sharing unique information in order to successfully solve such a task. The fifth phase began a new topic about photosynthesis and included background reading; quiz questions were used to ensure that students read the information found in the text. The sixth phase included Task A or Task B depending on which version of the ILS was used. The seventh phase involved students completing an adapted version of the self-assessed collaboration skills questionnaire. The remaining

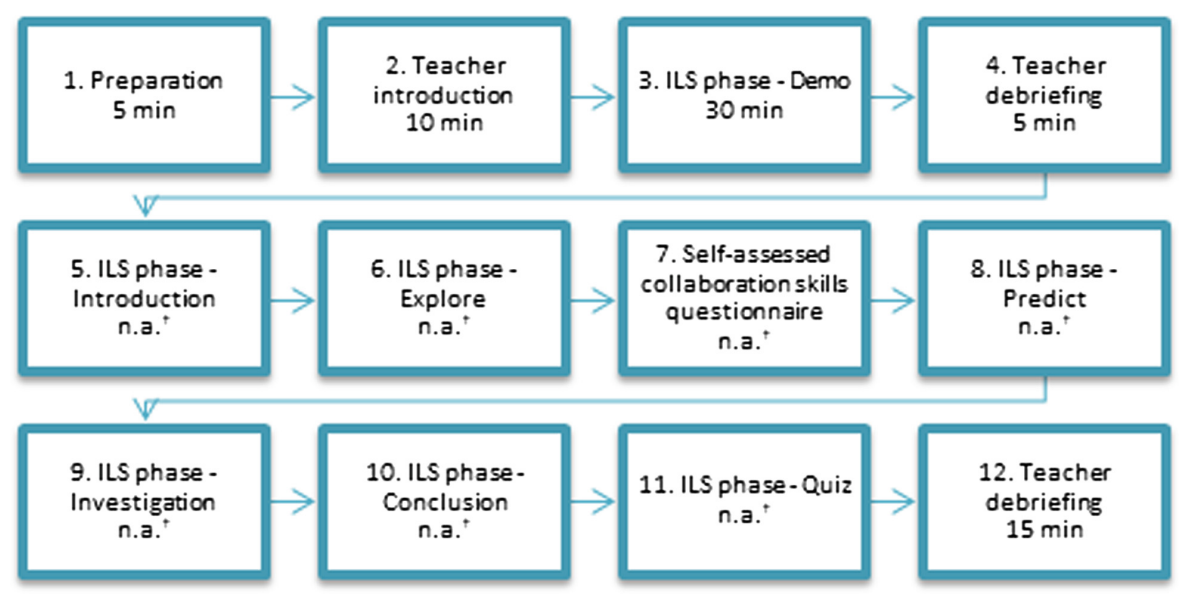

Fig. 2. Lesson plan of this study showing various inquiry phases, the approximate amount of time spent in a phase, learning activities and learning objectives. †The time for phases 5 to 11 was not separately determined since groups worked at their own pace, but altogether lasted about $70 \mathrm{~min}$. See the ILS links https://graasp.eu/s/cw6fmu or https://graasp.eu/s/unlxjc for details regarding the exact content in an ILS phase. 
phases involved generating a hypothesis, conducting experiments with another simulation about the effect of temperature on photosynthesis, making conclusions, answering a post-test quiz and a debriefing by the teacher. They were not the focus of this study and therefore not discussed further. The final debriefing by the teacher, phase 12, did include a review and demonstration of the correct responses to Tasks A and B.

\section{Results and Discussion}

The aim of this research was to study how group size affects students' inquiry and collaboration in using computer-based asymmetric inquiry tasks. Tasks A and B were used to assess students' inquiry and an adapted self-assessed collaboration skills questionnaire used to assess their collaboration.

Table 1 presents the inquiry scores for $5^{\text {th }}$ and $6^{\text {th }}$ grade groups. Although 2-person groups performed better than 4-person groups on the combined score of Tasks A and B, the results did not reach statistical significance. The highest score was obtained from $6^{\text {th }}$ grade students working in pairs $(61 \%)$ and the lowest score from $5^{\text {th }}$ grade students working in 4-person groups (20\%). Analysis of students' collaboration (Table 2), shows that group size did not statistically significantly differ in the dimensions of sharing, support or learning for $5^{\text {th }}$ grade groups, but did for $6^{\text {th }}$ grade groups. Students working in pairs in the $6^{\text {th }}$ grade reported higher collaboration skills in all dimensions of collaboration compared to students working in 4-person groups.

One possible reason why $6^{\text {th }}$ grade students reported better collaboration in 2person groups is because they are more experienced working in such sized groups. At the school where they study, the students start working in the open classroom beginning in 4th grade for math and science lessons. The teacher we co-created the lesson plan with describes that group work is most often in pairs. Accordingly, by the sixth grade, students have ample experience with pair work and may prefer it compared to larger sized group work. The teacher also mentioned that social loafing can be an issue with larger sized groups.

Table 1. Inquiry scores for $5^{\text {th }}$ and $6^{\text {th }}$ grade groups. Tasks A and B were each scored out of a maximum of 2 points.

\begin{tabular}{l|l|l|l|l|l|l|l|l}
\hline Grade & Inquiry task & \multicolumn{2}{|l|}{ 2-person groups } & \multicolumn{3}{l|}{ 4-person groups } & \multicolumn{3}{|c}{ Mann-Whitney U } \\
\cline { 3 - 9 } & & $\mathrm{N}$ & $\mathrm{M}(\mathrm{SD})$ & $\mathrm{N}$ & $\mathrm{M}(\mathrm{SD})$ & $\mathrm{U}$ & $\mathrm{Z}$ & $\mathrm{p}$ \\
\hline \multirow{3}{*}{5} & Task A & 10 & $0.90(0.88)$ & 10 & $0.40(0.70)$ & 33.5 & -1.384 & .166 \\
\cline { 2 - 10 } & Task B & 10 & $0.20(0.63)$ & 10 & $0.40(0.84)$ & 45.0 & -.610 & .542 \\
\cline { 2 - 9 } & Task A + B & 10 & $1.10(1.29)$ & 10 & $0.80(1.32)$ & 40.5 & -.776 & .438 \\
\hline \multirow{6}{*}{6} & Task A & 7 & $1.14(0.90)$ & 15 & $0.67(0.72)$ & 36.0 & -1.244 & .213 \\
\cline { 2 - 9 } & Task B & 7 & $1.29(0.95)$ & 15 & $0.87(0.99)$ & 40.5 & -.938 & .348 \\
\cline { 2 - 9 } & Task A + B & 7 & $2.43(1.40)$ & 15 & $1.53(1.13)$ & 31.0 & -1.582 & .114 \\
\hline
\end{tabular}


Table 2. Self-assessed collaboration ratings of $5^{\text {th }}$ and $6^{\text {th }}$ grade individuals. Items were rated on a 7-point Likert scale ranging from completely disagree to completely agree.

\begin{tabular}{l|l|l|l|l|l|l|l|l}
\hline \multirow{2}{*}{ Grade } & $\begin{array}{l}\text { Collaborative } \\
\text { dimension }\end{array}$ & \multicolumn{2}{l|}{$\begin{array}{l}\text { Individuals in } \\
\text { 2-person groups }\end{array}$} & \multicolumn{2}{l}{$\begin{array}{l}\text { Individuals in } \\
\text { 4-person groups }\end{array}$} & \multicolumn{3}{l}{ Mann-Whitney $U$} \\
\cline { 3 - 9 } & & $N$ & $M(\mathrm{SD})$ & $N$ & $M(\mathrm{SD})$ & \multicolumn{1}{l}{$U$} & \multicolumn{1}{l}{$Z$} & $p$ \\
\hline \multirow{5}{*}{5} & Sharing & 20 & $6.0(1.4)$ & 38 & $5.9(1.6)$ & 379.0 & -0.18 & .986 \\
\cline { 2 - 9 } & Support & 20 & $5.6(1.6)$ & 38 & $5.5(1.6)$ & 361.0 & -.316 & .752 \\
\cline { 2 - 9 } & Learning & 20 & $4.8(1.7)$ & 38 & $5.2(1.9)$ & 306.5 & -1.235 & .217 \\
\hline \multirow{6}{*}{6} & Sharing & 14 & $6.9(0.5)$ & 60 & $5.4(1.2)$ & 130.5 & -4.891 & $<.001$ \\
\cline { 2 - 9 } & Support & 14 & $6.9(0.2)$ & 60 & $5.2(1.4)$ & 71.0 & -4.891 & $<.001$ \\
\cline { 2 - 9 } & Learning & 14 & $6.1(0.9)$ & 60 & $5.3(1.3)$ & 266.0 & -2.226 & .026 \\
\hline
\end{tabular}

As previously mentioned, inquiry task scores were higher for 2-person groups but did not reach statistical significance. The inquiry scores were generally poor for all groups (see Table 1). To better understand why scores were low, we analyzed the types of errors students made in solving the inquiry tasks. Three types of errors were coded:

1. Syntax. These errors relate to students answering the open-ended questions ambiguously or using poor grammar, e.g. "bubbles coming", "then bubbles come faster", "In winter, the plant makes less nutrients."

2. Collaboration. These errors relate to a student not answering his or her task question but answering as if they had the same question as their partner.

3. Inquiry. These errors relate to students not thoroughly conducting experiments in the simulation, such as changing more than one variable at a time and thereby obtaining incorrect results, e.g., "Slowly in winter (every 10-30 s) but fast in summer (every $6 \mathrm{~s}$ )".

The error categories were independently coded by two raters and a good interrater reliability (kappa $=.73$ ) was obtained. Table 3 summarizes the results of the error analysis in terms of number of errors made by the different groups. Students working in 4-person groups made more errors and in the $5^{\text {th }}$ grade the types of errors were mostly Syntax. In the $6^{\text {th }}$ grade the errors were also mostly Syntax, but also several errors were made in the Inquiry type. In addition, 2-person groups in the $6^{\text {th }}$ grade made the least amount of errors. Sixth grade students have the most practice working in 2-person groups, and therefore one may hypothesize that this might be the reason why they made fewer mistakes compared to the other groups. Task A students did not make Inquiry type errors. Only Task B students made these errors, indicating that it was easier to answer the question about how light intensity affects the rate of photosynthesis, perhaps relying on prior knowledge rather than conducting experiments, compared to answering the question about the influence of the season of the year variable. 
Table 3. Number of errors made by grade 5 and grade 6 students on Tasks A and B.

\begin{tabular}{|c|c|c|c|c|c|c|c|c|c|}
\hline \multirow[t]{3}{*}{ Task } & \multirow{3}{*}{$\begin{array}{l}\text { Error } \\
\text { category }\end{array}$} & \multicolumn{4}{|c|}{$5^{\text {th }}$ grade groups } & \multicolumn{4}{|c|}{$6^{\text {th }}$ grade groups } \\
\hline & & \multicolumn{2}{|c|}{ 2-person } & \multicolumn{2}{|c|}{ 4-person } & \multicolumn{2}{|c|}{ 2-person } & \multicolumn{2}{|c|}{ 4-person } \\
\hline & & $\mathrm{N}$ & $\begin{array}{l}\text { No. of } \\
\text { errors }\end{array}$ & $\mathrm{N}$ & $\begin{array}{l}\text { No. of } \\
\text { errors }\end{array}$ & $\mathrm{N}$ & $\begin{array}{l}\text { No. of } \\
\text { errors }\end{array}$ & $\mathrm{N}$ & $\begin{array}{l}\text { No. of } \\
\text { errors }\end{array}$ \\
\hline \multirow[t]{3}{*}{ A } & Syntax & 10 & 3 & 10 & 6 & 7 & 0 & 15 & 5 \\
\hline & Collaboration & 10 & 0 & 10 & 1 & 7 & 0 & 15 & 2 \\
\hline & Inquiry & 10 & 0 & 10 & 0 & 7 & 0 & 15 & 0 \\
\hline \multirow[t]{4}{*}{ B } & Syntax & 10 & 2 & 10 & 2 & 7 & 0 & 15 & 2 \\
\hline & Collaboration & 10 & 3 & 10 & 2 & 7 & 2 & 15 & 1 \\
\hline & Inquiry & 10 & 3 & 10 & 2 & 7 & 0 & 15 & 5 \\
\hline & Total & & 11 & & 13 & & 2 & & 15 \\
\hline
\end{tabular}

Similar to the poor performance on the hidden profile task, working on asymmetric collaborative inquiry tasks proved to be challenging for students. However, unlike the hidden profile task, the asymmetric collaborative inquiry activity in this study strongly suggested to students the need to unshared information in order to successfully solve the tasks (i.e., a demo activity with a practice asymmetric collaborative simulation explicitly highlighted the importance of relying on unshared information and the main task itself asked students to examine a variable that their version of the simulation did not even allow on to manipulate). Nevertheless, task performance was generally low for both $5^{\text {th }}$ and $6^{\text {th }}$ grade students $\left(35 \%\right.$ and $25 \%$ for $5^{\text {th }}$ grade 2-person and 4-person groups, and $71 \%$ and $50 \%$ for $6^{\text {th }}$ grade 2-person and 4-person groups respectively). Similarly, Chang et al. [24] studied asymmetric collaboration in the context of physics problem-solving and found that 6 out of 10 groups were unable to formulate plans that would have led them to successfully solve their problem. All in all, the results suggest that more guidance or practice may be necessary for students to perform better on asymmetric collaboration inquiry activities. Particularly interesting would be a longitudinal study to see whether practice with different asymmetric collaborative simulations, over several lessons, has an effect on students' inquiry and collaboration. In addition to the two simulations used in this study, the Go-Lab portal (golabz.eu) currently offers two other asymmetric collaborative simulations: the Collaborative Rabbit Genetics Lab (https://www.golabz.eu/lab/collaborative-rabbit-genetics-lab) and the Collaborative Dollhouse Electricity Lab (https://www.golabz.eu/lab/collaborativedollhouse-electricity-lab).

\section{Conclusion}

As interest towards integrating collaboration skills with inquiry learning increases, we believe that asymmetric collaborative simulations offer a promising way to structure a beneficial learning experience. However, more research is needed to study the instructional conditions and support that can best utilize the potential of asymmetric collaboration for enhanced inquiry learning. 
We also have to keep in mind that teachers play a crucial role in supporting students' collaborative learning. Van Leeuwen and Janssen [25], in a review of teacher guidance during collaborative learning, highlight that teachers can facilitate productive collaborative learning by giving feedback, prompting and questioning students, and guiding students to be self-directed learners. These general strategies are also promising for supporting collaborative inquiry learning.

In the future, a longitudinal study should be carried out with a larger sample size where students are more supported in asymmetric collaboration and with inquiry-tasks that cover a range of different subjects.

Acknowledgements. This work was partially funded by the European Union in the context of the Next-Lab innovation action (Grant Agreement 731685) under Research and Innovation H2020 Framework Programme. In addition, this study was partly sponsored by the Estonian Research Council (ERC) through the institutional research funding project "Smart technologies and digital literacy in promoting a change of learning" (Grant Agreement No. IUT34-6). This document does not represent the opinion of the European Union or ERC, and these organizations are not responsible for any use that might be made of its content.

\section{References}

1. National Research Council: Assessing 21st Century Skills: Summary of a Workshop. The National Academies, Washington, DC (2011)

2. Griffin, P., Care, E.: Assessment and Teaching of 21st Century Skills: Methods and Approach. Springer, Dordrecht (2015)

3. OECD: PISA 2015 Results (Volume V): Collaborative Problem Solving. PISA, OECD Publishing, Paris (2017)

4. Dunbar, K.: How scientists think: on-line creativity and conceptual change in science. In: Ward, T.B., Smith, S.M., Vaid, J. (eds.) Creative Thought: An Investigation of Conceptual Structures and Processes, pp. 461-493. American Psychological Association, Washington (1997)

5. Dillenbourg, P.: What do you mean by "collaborative learning"? In: Dillenbourg, P. (ed.) Collaborative Learning: Cognitive and Computational Approaches, pp. 1-16. Elsevier Science, Amsterdam (1999)

6. Chen, J., Wang, M., Kirschner, P.A., Tsai, C.-C.: The role of collaboration, computer use, learning environments, and supporting strategies in CSCL: a meta-analysis. Rev. Educ. Res. 88(6), 799-843 (2018)

7. Lohman, M.C., Finkelstein, M.: Designing groups in problem-based learning to promote problem-solving skill and self-directedness. Instr. Sci. 28(4), 291-307 (2000)

8. Slavin, R.E.: Ability grouping and student achievement in elementary schools: a bestevidence synthesis. Rev. Educ. Res. 57(3), 293-336 (1987)

9. Wiley, J., Jensen, M.: When three heads are better than two. In Proceedings of the 28th Annual Conference of the Cognitive Science Society, pp. 2375-2380 (2006)

10. Sung, Y.T., Yang, J.M., Lee, H.Y.: The effects of mobile-computer-supported collaborative learning: meta-analysis and critical synthesis. Rev. Educ. Res. 87(4), 768-805 (2017)

11. Koh, E., Shibani, A., Tan, J.P.-L., Hong, H.: A pedagogical framework for learning analytics in collaborative inquiry tasks: an example from a teamwork competency awareness program. In: Proceedings of the Sixth International Conference on Learning Analytics \& Knowledge (LK 74-83). ACM, New York (2016) 
12. Ofstedal, K., Dahlberg, K.: Collaboration in student teaching: introducing the collaboration self-assessment. J. Early Child. Teacher Educ. 30(1), 37-48 (2009)

13. Hinyard, L., Toomey, E., Eliot, K., Breitbach, A.: Student perceptions of collaboration skills in an interprofessional context: development and initial validation of the self-assessed collaboration skills instrument. Eval. Health Prof. (2018). https://doi.org/10.1177/ 0163278717752438

14. Johnson, D.W., Johnson, R.T.: Making cooperative learning work. Theory Pract. 38(2), 6773 (1999)

15. Stasser, G., Titus, W.: Pooling of unshared information in group decision making: biased information sampling during discussion. J. Pers. Soc. Psychol. 48(6), 1467 (1985)

16. Wittenbaum, G.M., Hollingshead, A.B., Botero, I.C.: From cooperative to motivated information sharing in groups: moving beyond the hidden profile paradigm. Commun. Monogr. 71(3), 286-310 (2004)

17. Lu, L., Yuan, Y.C., McLeod, P.L.: Twenty-five years of hidden profiles in group decision making: a meta-analysis. Pers. Soc. Psychol. Rev. 16(1), 54-75 (2012)

18. Cruz, M.G., Boster, F.J., Rodríguez, J.I.: The impact of group size and proportion of shared information on the exchange and integration of information in groups. Commun. Res. 24(3), 291-313 (1997)

19. Stasser, G., Taylor, L.A., Hanna, C.: Information sampling in structured and unstructured discussions of three-and six-person groups. J. Pers. Soc. Psychol. 57(1), 67 (1989)

20. Mennecke, B.E.: Using group support systems to discover hidden profiles: an examination of the influence of group size and meeting structures on information sharing and decision quality. Int. J. Hum Comput. Stud. 47(3), 387-405 (1997)

21. de Jong, T., Sotiriou, S., Gillet, D.: Innovations in STEM education: the Go-Lab federation of online labs. Smart Learn. Environ. 1(1), 3 (2014)

22. Siiman, Leo A., et al.: Design and evaluation of a smart device science lesson to improve students' inquiry skills. In: Xie, H., Popescu, E., Hancke, G., Fernández Manjón, B. (eds.) ICWL 2017. LNCS, vol. 10473, pp. 23-32. Springer, Cham (2017). https://doi.org/10.1007/ 978-3-319-66733-1_3

23. Pedaste, M., et al.: Phases of inquiry-based learning: definitions and the inquiry cycle. Educ. Res. Rev. 14, 47-61 (2015)

24. Chang, C.J., et al.: An analysis of student collaborative problem solving activities mediated by collaborative simulations. Comput. Educ. 114, 222-235 (2017)

25. van Leeuwen, A., Janssen, J.: A systematic review of teacher guidance during collaborative learning in primary and secondary education. Educ. Res. Rev. 27, 71-89 (2019)

Open Access This chapter is licensed under the terms of the Creative Commons Attribution 4.0 International License (http://creativecommons.org/licenses/by/4.0/), which permits use, sharing, adaptation, distribution and reproduction in any medium or format, as long as you give appropriate credit to the original author(s) and the source, provide a link to the Creative Commons license and indicate if changes were made.

The images or other third party material in this chapter are included in the chapter's Creative Commons license, unless indicated otherwise in a credit line to the material. If material is not included in the chapter's Creative Commons license and your intended use is not permitted by statutory regulation or exceeds the permitted use, you will need to obtain permission directly from the copyright holder.

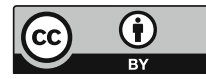

